\title{
Verbal conditioning, task instructions, and inhibition of the GSR measure of the orienting reflex
}

\author{
IRVING MALTZMAN, CARL VINCENT, and CRAIG WOLFF \\ University of California, Los Angeles, California
}

\begin{abstract}
One-hundred and twenty-eight college students participated in an experiment designed to examine facilitatory and inhibitory effects of instructions on the GSR index of the orienting reflex. One aspect of the study examined effects of instructions on verbal differential semantic conditioning of the GSR and conventional differential semantic conditioning requiring discovery of the CS-US contingency. A forewarned reaction time paradigm was employed with an innocuous imperative stimulus as the UCS. Reliable verbal differential semantic conditioning was obtained, as well as conventional differential conditioning. It was also found that orienting to one innocuous stimulus resulted in a significant decrease in the magnitude of the GSR induced by a second innocuous stimulus. An account in terms of inhibitory properties of orienting reflexes was proposed to account for the latter result.
\end{abstract}

Given the appropriate background or standing conditions, three kinds of initial conditions may give rise to an orienting reflex (OR) as reflected in a measure such as the GSR: (1) external stimulus changes of various kinds (Sokolov, 1963) summaarized collectively as collative variables by Berlyne (1960), (2) the significance of stimuli, learned or unlearned (Bernstein, 1979; Maltzman, 1979; O'Gorman, 1979; Pendery \& Maltzman, 1977; Razran, 1971; Sokolov, 1963), and (3) self-generated ORs as reflected in problem-solving activity (Maltzman, 1979; Maltzman \& Mandell, 1968; Pendery \& Maltzman, 1977). Different aspects of the present study are concerned with the second and third classes of OR determiners.

\section{Verbal Conditioning}

For many years, it had been assumed that verbal conditioning of the GSR (Cook \& Harris, 1937) was accomplished via the mediation of anxiety (Bandura, 1969; Mowrer, 1939). If subjects are informed that they will receive an electric shock which will be preceded or signaled by the occurrence of an innocuous

The studies reported here were made possible in part by funds provided by the Carnegie Corporation of New York and from Public Health Service Research Grant MH 04684 from the National Institute of Mental Health. For the analyses of the results of experiments reported here, computing assistance was obtained from the Health Science Computing Facility, UCLA, sponsored by National Institute of Health Grant FR-3. Craig Wolff is now at International Rehabilitation Associates, Incorporated. Requests for reprints should be sent to Irving Maltzman, Department of Psychology, University of California, Los Angeles, California 90024.

Article accepted by previous editor, Richard F. Thompson auditory stimulus, the first presentation of the auditory stimulus will evoke a large GSR prior to the appearance of the shock UCS on the first conditioning trial (Bridger \& Mandel, 1964; Cook \& Harris, 1937; Dawson \& Grings, 1968).

Pendery and Maltzman (1977, 1979), however, demonstrated that the same kind of effect, highly reliable differential semantic conditioning of the GSR by verbal conditioning, may be produced with an innocuous UCS, a tone signaling a response in a forewarned reaction time situation. Some students received the tone after each word in the habituation series and were instructed to respond to the tone only when they heard it follow a particular word. The students who received the tone all through the habituation series preceding conditioning did not differ in the extent of their verbal conditioning from students who heard the tone for the first time when conditioning began. It is reasonable to assume, therefore, that the GSR-CR on the first trial was not the consequence of uncertainty or fear of an unknown tone. An interpretation offered for these verbal conditioning results (Pendery \& Maltzman, 1977) was that the GSR evoked upon the first presentation of the CS was a manifestation of a voluntary OR induced by the noteworthy, or significant, stimulus, significant because of the signal value imparted to it by the instructions. It was further suggested that since verbal conditioning can be produced with an innocuous UCS and therefore cannot be attributed to mediated anxiety, earlier experiments producing verbal conditioning (e.g., Cook \& Harris, 1937; Dawson \& Grings, 1968) using noxious UCSs were in all likelihood also the consequence of GSRs mediated by ORs rather than by anxiety. 
Conditioning in subjects uninformed of the CSUCS contingency was also studied by Pendery and Maltzman (1977). Examination of GSR responsivity to critical and filler stimuli by individual subjects who discovered and subsequently verbalized the CSUCS contingency suggested that "conditioning" in the individual subject is a problem-solving discovery process. Participants, if successful, discover the significance of the CS as a signal for the UCS. This discovered significance is accompanied by an OR which is manifested as a large GSR taken as the CR by the experimenter. Basically, then, verbal and conventional conditioning of the GSR involves the elicitation of an OR by a noteworthy or significant stimulus. In one case, the significance is imparted by instructions; in the other, it is discovered by the participant.

Conditioning in our experiments (Maltzman, 1977) is manifest only among those students who can verbalize the discovered contingency between CS and UCS, although not every one of the verbalizers does show conditioning. On the other hand, none of the students who fail to verbalize the contingency manifest differential conditioning. A relationship of this sort between verbalization of CS-UCS contingencies and conditioning of the GSR is the characteristic (e.g., Dawson \& Furedy, 1976), but by no means universal, finding (Brandeis \& Lubow, 1975). One purpose of the present experiment was an attempt to enhance verbal and conventional conditioning by varying the kinds of instructions given participants in the two groups. For the latter purpose, half the students within each of the four principal groups were instructed to search for a rule, and half were not.

\section{OR-Induced Inhibition}

Much of the interest, theoretical and experimental, originally engendered by the theoretical conception of the OR (Sokolov, 1963, 1969) stemmed from the assumed functional relationships it has with other important processes. Orienting reflexes under appropriate, although not entirely specified, conditions may facilitate learning and perception (e.g., Sokolov, 1963; Voronin, Leontiev, Luria, Sokolov, \& Vinogradova, 1965). Evocation of an OR by a novel stimulus may increase sensitivity, that is, lower the perceptual threshold, for a second target stimulus (Steklova, 1965).

Another functional property of ORs has been relatively neglected. Under appropriate, but poorly specified, conditions, elicitation of an OR may inhibit, or interfere with, the occurrence of other ORs and, by implication, the processing of the second stimulus in the central nervous system. Some evidence suggests that such an inhibitory effect may be induced between innocuous stimulus (Maltzman, Harris, Ingram, \& Wolff, 1971) as well as between an innocuous and noxious stimulus (Maltzman \& Wolff, 1970; Waid, 1979). When, as in the latter case, the innocuous stimulus has been used as a warning signal for a subsequent noxious stimulus, the interpretation and results have been a point of controversy (Furedy, 1975).

In contrast to the latter kind of study, which is concerned with the controversial issue of whether or not a warning signal prepares an organism to cope with or somehow attenuate the effects of a noxious stimulus, the present study is concerned with the possible inhibitory effect of one innocuous stimulus upon the GSR induced by a subsequent innocuous stimulus. Furthermore, initially the participants had no foreknowledge that the first stimulus was always followed by the second in the present study.

Whether or not orienting to a given stimulus may inhibit an OR to a subsequent stimulus was examined in relation to the GSRs evoked by the tones presented an an imperative stimulus for a verbal conditioning group (T) and a conventional conditioning group (D) requiring discovery of the CS-UCS contingency. Both Group $T$ and Group D were instructed to respond to the tone. Group $\mathrm{T}$, in addition, was informed that the word PLANT always preceded the tone. On the basis of our observations in a previous experiment (Maltzman, Gould, Barnett, Raskin, \& Wolff, 1977), it was expected that large GSR-ORs would be evoked by the tone in both groups. Two additional groups were not instructed to respond to the tone. Group $\mathbf{P}$ was instructed to respond to PLANT. Students in Group $P$ were not informed that PLANT always preceded a tone. Group L was not instructed to overtly respond to any stimulus. All students in Group L were informed that they would hear words and tones. Our major interest here was to determine whether the GSRs evoked by the tone in the latter two groups, Groups $P$ and L, would differ. We hypothesized that the relatively large OR evoked to PLANT in Group P would result in inhibition of the OR induced by the tone, a relatively novel stimulus, as compared with responsivity to the tone in Group L. For neither group was the tone a significant stimulus possessing signal value for a motor response. They differed in that PLANT was a significant stimulus for students in Group P, who had been instructed to respond to it, whereas no stimulus had been explicitly bestowed with significance for Group L. We assumed that if the OR had inhibitory properties, then orienting to PLANT might result in a reduced OR and smaller GSR to the tone in Group $P$ than in Group L. There should be some orienting to the tone in both conditions, since the tone was a relatively novel stimulus interspersed among words.

In consciousness-centered terms, we wished to determine whether or not concentration of attention (Külpe, 1895) upon one stimulus, the word PLANT, 
might inhibit attention to a stimulus that followedthe tone.

\section{METHOD}

\begin{abstract}
Subjects
There were 128 University of California, Los Angeles introductory psychology students participating in the experiment in partial fulfillment of a course requirement. Half of the 16 participants in each of eight subgroups were men, and half were women. Since the nature of the experiment demanded participants who verbalized the CS-UCS contingency in the noninstructed groups, a larger number of students were examined in the "discovery" and "listen" groups in order to obtain an equal number of men and women in each subgroup.
\end{abstract}

\section{Procedure}

Four principal groups were employed, tone (T), discovery (D), plant (P), and listen (L). Groups $T$ and $D$ were concerned primarily with the conditioning problem, whereas Groups $\mathrm{P}$ and $\mathrm{L}$ were designed to examine the problem of inhibition. All groups received the same stimulus materials but differed in their task instructions. Group T subjects were instructed to provide a pedal response whenever they heard a tone, and were further told that the tone always followed the word PLANT. They constituted a verbal conditioning group. Group D, the discovery group, was a standard conditioning group (e.g., Pendery \& Maltzman, 1977). These subjects were instructed to provide a pedal response to the tone, but were not told that the tone followed PLANT or any other specific word. Group P participants were instructed to provide a pedal response, that is, to lift their feet off a pedal, whenever they heard the word PLANT. Group L served as a "control" group. These subjects were instructed to sit quietly and listen, and were told that they would hear words and occasional tones. There was no overt response requirement in this condition. Half the students within each of the above four groups were instructed to search for a rule, Condition R; the other half were told nothing about a rule, Condition NR. Neither the word PLANT nor the tone was presented during a 20 -word habituation series that preceded the conditioning phase of the experiment. Semantic conditioning followed the habituation series without interruption. There were six conditioning trials in which the word PLANT was followed in $10 \mathrm{sec}$ by the presentation of a $.5-\sec 1,000-\mathrm{Hz}$ tone at approximately $70 \mathrm{~dB}(\mathrm{~A})$. Two to four neutral filler words were interspersed between conditioning trials. Interword intervals and the interval between the tone and a subsequent word varied from 12 to $18 \mathrm{sec}$. All words were high-frequency common words (Thorndike \& Lorge, 1944) and, except for the CS words, were presented only once during the course of the experiment.

Since different instructions were given the various groups prior to habituation, a $.5-\sec 1,000-\mathrm{Hz}$ tone at approximately $70 \mathrm{~dB}(\mathrm{~A})$ was presented $20 \mathrm{sec}$ prior to the instructions. This was done in order to obtain a measure of the initial OR uncontaminated by possible effects of the different instructions. All instructions, as well as the words, were prerecorded on magnetic tape and presented via stereophonic headphones.

Following completion of the experiment, the students were administered a lengthy questionnaire designed to determine the extent to which they verbalized the CS-UCS contingency and recalled various aspects of the experiment.

The experiment was conducted in an experimental setting with a GSR recording arrangement that has previously been described (Pendery \& Maltzman, 1977). Bipolar palmar GSRs were recorded using two $20-\mathrm{mm}$ circular disk electrodes fitted in 5 -mm-deep plastic cups. The cups contained electrode paste made from agar and a $1 \%$ zinc sulfate solution. GSR electrodes were held in place by plastic pressure clips encased in foam rubber. Using a $40-\mu \mathrm{A}$ current, palmar resistance was continuously monitored via a
Darrow-type bridge on one channel of a dual-channel dc Sanborn 320 amplifier recorder. The GSR was scored as the largest resistance change occurring within the interval $.5-5.5 \mathrm{sec}$ following the CS word PLANT and the different preceding and following filler words, all words in the habituation series, and each presentation of the tone. Prior to statistical analyses, the GSR was subjected to a log conductance change transformation. The .05 confidence level for a two-tailed test was employed in all statistical analyses.

\section{RESULTS AND DISCUSSION}

Distributions of the magnitude of the GSR to the $1,000-\mathrm{Hz}$ tone presented prior to instructions and the habituation series were determined for males and females separately within each of the eight subgroups. Students above the median for a given response distribution were designated as high-OR students, whereas students below the median were designated low-OR students. Analysis of variance of the magnitude of the GSR to this first tone indicated no reliable differences reflecting possible sampling biases between the sexes or the groups subsequently formed as a result of different kinds of instructions.

\section{Conditioning}

Figure 1 depicts the mean magnitudes of the GSR induced by the CS word and the immediately preceding, $C_{1}$, and following, $C_{2}$, control words for each of the six conditioning trials. Combined rule and norule instructed groups are shown in the left panel. Combined discovery (D) groups are depicted in the right panel of Figure 1. Subgroups were combined for display since instructions to search for a rule did not produce a significant main effect or interactions with words.

Analyses of variance and orthogonal polynomials indicated that words yielded a significant effect $[F(2,64)=198.09]$, supporting the obvious impression from Figure 1 of the presence of differential semantic conditioning in both groups. A significant groups $\times$ words interaction was obtained, instructed vs. discovery groups $[\mathrm{F}(2,64)=21.00]$, indicating superior differential conditioning in the instructed group, $\mathrm{T}$, as compared with the discovery group, D. Not shown in Figure 1 was a significant $O R \times$ words interaction $[F(2,64)=16.17]$, reflecting the superior differential conditioning on the part of high- as contrasted with low-OR students. The $\mathrm{OR} \times$ groups $\times$ words interaction was also significant $[F(2,64)=$ $9.75, \mathrm{MS}=.365$, primarily because the low-OR students in Group D failed to show appreciable differential conditioning.

It is interesting to note that the levels of high-/lowOR that are related to differential semantic conditioning were established by a categorization on the basis of the magnitude of the GSR induced by a tone presented prior to the start of the experiment. Although a GSR induced in such a manner is as- 


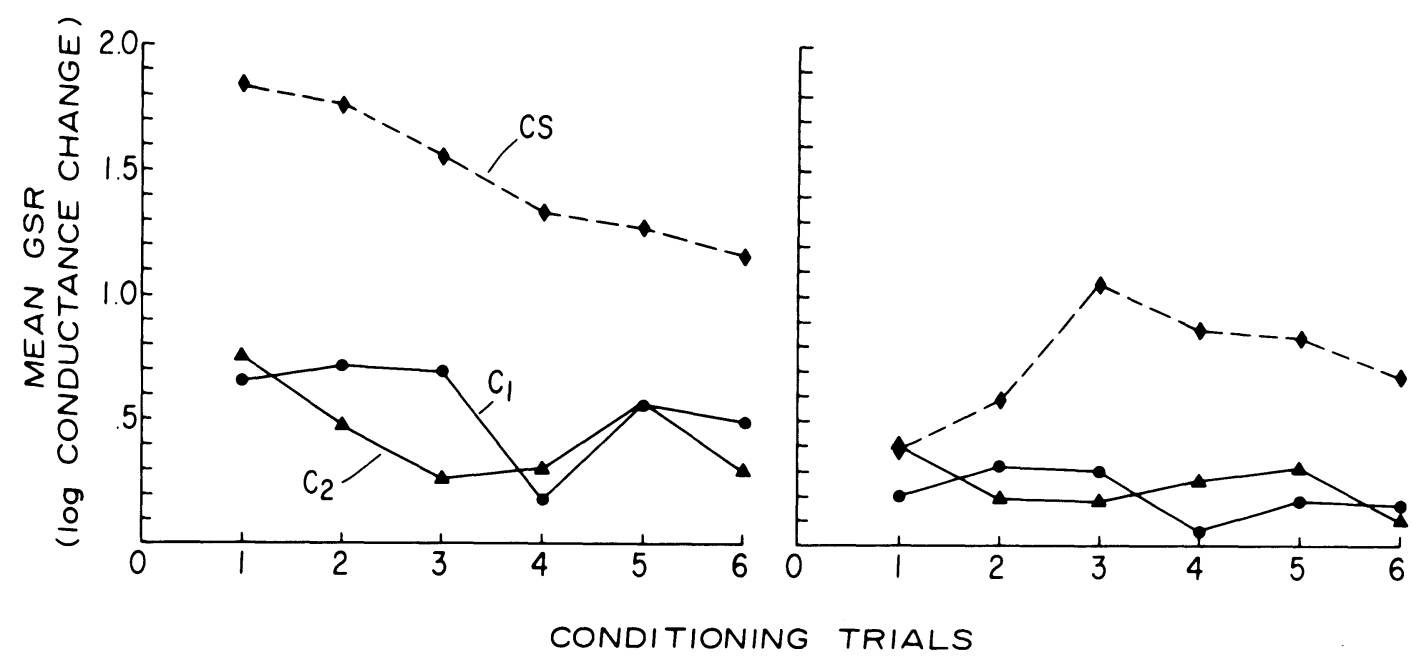

Figure 1. Mean magnitude of the galvanic skin responses (GSRs) evoked by the conditioned stimulus (CS) and the preceding, $C_{1}$, and following, $C_{2}$, control words on each of the six conditioning trials. Results obtained in the verbal conditioning group ( $T$ ) are displayed in the left panel, and results obtained with the conventional conditioning group (D) are displayed in the right panel.

sumed to be the reflection of a relatively involuntary OR (Maltzman, 1977, 1979), it is nevertheless related to subsequent differential semantic conditioning assumed to be the consequence of a voluntary OR induced by the discovered significance of the CS (Pendery \& Maltzman, 1977).

Habituation of the GSR induced by the CS apparent in Group $T$ is reflected in the significant interaction in linear components of the trends, group $x$ words $\left[\mathrm{F}(2,64)=9.71, \mathrm{MS}_{\mathrm{W}}=.305\right]$. Table 1 shows the $\mathrm{L}$ scores for the GSRs to the control and CS words in Groups T and D. It is apparent that the response trend to the CS in the instructed group had a relatively large negative component, whereas the principal linear component in the discovery group response trend to the CS was positive.

As Maltzman (1977) has noted, it is the rapid habituation of the GSR to the CS found in the usual classical conditioning experiment that has mislead some investigators to assume that classical conditioning is primarily a habituation phenomenon (Stern \& Walrath, 1977). They have failed to recognize that in their conditioning situations response magnitude is asymptotic following a small number of conditioning

Table 1

Linear Components of the Galvanic Skin Response (GSR) Trends to the CS and Preceding $\left(C_{1}\right)$ and Following $\left(C_{2}\right)$ Control Words in Tone Instructed $(T)$ and Discovery (D) Groups

\begin{tabular}{lcrc}
\hline & \multicolumn{3}{c}{ Words } \\
\cline { 2 - 4 } \multicolumn{1}{c}{ Group } & $\mathrm{C}_{1}$ & $\mathrm{CS}$ & $\mathrm{C}_{2}$ \\
\hline Tone Instructed & -.21 & -.60 & -.23 \\
Discovery & -.10 & .26 & -.12 \\
\hline
\end{tabular}

trials for those participants discovering the CS-UCS contingency. In a simple conditioning situation, the great majority of college students very quickly discover the contingency and therefore orient to the significant CS. Magnitude of the GSR to the significant CS then habituates, provided that the experimental contingencies do not change. If response magnitudes are averaged over trial blocks, as is the usual practice, the initial growth phase will be overlooked, leaving the principal component in the response trend one that reflects declining responsivity.

\section{Inhibition}

Figure 2 depicts the mean magnitude of the GSRs evoked by the tone in the four major groups on each of the six trials. Rule and no-rule subgroups were combined, since analyses of variance indicated that they failed to enter into any significant main effects or interactions. Figure 2 shows that Group L, the listen group, obtained consistently larger mean GSRs to the tone than did Group P, the group instructed to respond to the word PLANT preceding the tone. It is apparent that the response trends for Groups $P$ and $L$ did not diverge. A difference was apparent on the first trial and persisted through all six trials, suggesting that the difference in responsivity was not dependent upon the discovery that PLANT always signaled a subsequent tone. Foreknowledge based upon discovery of the CS-UCS contingency could not have been present prior to the first few trials. Since such foreknowledge is a necessary condition for coping, or preparedness, we may conclude that preparedness could not be the principal basis for the lower GSR responsivity to the tone displayed by Group $\mathrm{P}$ as compared with Group L. 


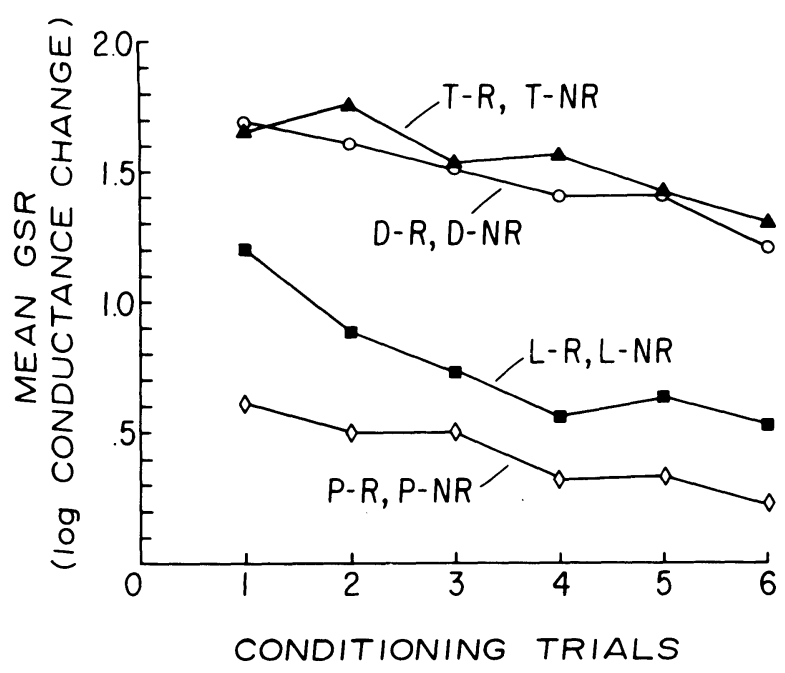

Figure 2. Mean magnitude of the galvanic skin responses (GSRs) evoked by the tone during conditioning trials for each of the four principal groups. Group $T$ was instructed to respond to the tone which always followed PLANT; Group D was instructed to respond to the tone and discovered that it always followed PLANT; Group $L$ was instructed only to listen; Group $P$ was instructed to respond to PLANT. Rule (R) and no-rule (NR) subgroups were combined in each of the four principal groups.

Analyses of variance and orthogonal polynomials comparing Groups $\mathrm{P}$ and $\mathrm{L}$ indicated that significant between-subject effects were obtained for groups $[F(1,32)=7.45]$, OR level $[F(1,32)=7.70]$, and $O R$ $\times$ groups $\left[\mathrm{F}(1,32)=5.81, \mathrm{MS}_{\mathrm{B}}=1.515\right]$. Examination of the mean GSRs reflected by the OR $\times$ groups interaction indicated that the superiority of Group L was primarily a consequence of the disproportionately greater responsivity to the tone of high-OR students in Group $L$ as compared with Group P. Low-OR students in Groups $P$ and $L$ obtained GSRs of .39 and .43 , respectively. High-OR students in Groups $P$ and $L$ obtained mean GSRs of .44 and 1.08, respectively. As is apparent from Figure 2, Groups T and D differed from Groups $L$ and $P$. A comparison of Groups $T$ and $L$ resulted in a significant main effect $\left[\mathrm{F}(1,320)=42.07, \mathrm{MS}_{\mathrm{B}}=\right.$ 1.390].

Figure 2 suggests that there is an overall decline in responsivity to the tones-habituation. Analyses of variance confirms the impression of declining responsivity, yielding a significant within-subject main effect [trials, $\mathrm{F}(5,160)=9.250, \mathrm{MSW}=.258$.]

\section{GENERAL DISCUSSION}

\section{Conditioning}

Results obtained from the conditioning phase of the present experiment replicate the essential findings previously reported by Pendery and Maltzman (1977, 1979). It is possible to verbally condition a differential GSR in the absence of the experience or the threat of a noxious stimulus. Maximum differential responding occurs with the first presentation of the CS word. Habituation of the GSR-CR, as well as GSRs induced by filler words, develops with continued conditioning trials (Maltzman, Weissbluth, $\&$ Wolff, 1978). Such results are in accord with the theoretical analysis offered by Pendery and Maltzman (1977) that the "conditioned" GSR in the usual laboratory experiment is mediated by a voluntary OR induced by the appearance of the critical word. The latter is a significant, or noteworthy, stimulus as a consequence of the task instructions. Evocation of a GSR-CR is mediated by a voluntary OR rather than by anxiety, according to the present theory (Maltzman, 1979; Pendery \& Maltzman, 1977).

Our additional manipulation of instructions informing half the students within each group to search for a rule was without discernible effect. The principal hoped-for effect, differential conditioning in the discovery group, did not differ for the rule and the no-rule subgroups. Interviews with students following completion of the experiment suggested some reasons for the absence of an effect attributable to the variation in instructions. Students' comments indicated that the instructions lead them to search for a complex, subtle, and nonobvious principle. When they discovered the contingency between the CS word and the tone, they tended to dismiss it and continued to search for some more esoteric relationship, believing that the experimenter could not have intended so simple a rule as the goal of their problem-solving search. Rather than facilitating Group D, students in the discovery of the CS-UCS contingency, it did nothing or may have misled them. Obviously, it had no significant effect, either facilitatory or inhibitory. In similar fashion, it did not influence GSR responsivity in the remaining three groups. Students engage in problem solving when they are placed in a classical conditioning situation (Pendery \& Maltzman, 1977). They do so without any explicit instructions urging them to that effect. General instructions to search for a rule do not seem capable of facilitating a solution to the problem of what leads to what when it is as simple as the CS-UCS contingency in the present type of experiment.

\section{Inhibition}

Instructing students in Group $P$ to perform an overt response to PLANT, utilizing it as a signal for a response, resulted in significantly smaller magnitude GSRs to the tone that followed in $10 \mathrm{sec}$ as compared with Group L students, who had been instructed to sit quietly and listen. Half the students within Groups $P$ and $L$ were told that there was a certain rule present among the stimuli, an instruction that had no differential effect.

At least three different theoretical interpretations are possible for the decreased responsivity to the tone displayed by Group P. First is a peripheral interfer- 
ence interpretation (Grings \& Schell, 1969). It suggests that the peripheral change in GSR induced by the first stimulus, the word PLANT, interacted with and reduced the magnitude of the GSR to the second stimulus, the tone. No general behavioral import can be ascribed to such results. There are several arguments that may be mustered against this peripheral interference interpretation: (1) The interstimulus interval of $10 \mathrm{sec}$ is longer than the range of interstimulus intervals demonstrated by Grings and Schell (1969) to have a significant interfering effect; (2) Grings and Schell (1969) studied the interaction between GSRs induced by two quite noxious forewarned stimuli so that the applicability of their results to unwarned innocuous stimuli is questionable; (3) Waid (1979) found that an 11-sec interstimulus interval between a warning signal and a noxious stimulus did not produce a peripheral interference effect; and (4) inspection of our chart recordings failed to reveal evidence of multiple responding or changes in base level just prior to the tone that could result in a reduction in the magnitude of the response induced by the tone.

A second interpretation of the decrement in GSR magnitude induced by the tone in Group $P$ is that the word PLANT induced a coping or preparedness process that attenuated the sensory characteristics of the tone. A reduction in the magnitude of the GSRs induced by the tone occurred as a consequence. The preparedness concept assumes a situation in which a noxious stimulus is preceded by a warning signal and participants are instructed concerning the contingency and make an effort to cope with the noxious stimulus. Conditions necessary for the occurrence of negative perception or coping (Lykken \& Tellegen, 1974) are therefore absent in the present experiment. Participants in Group P did not have foreknowledge that PLANT was always followed by an innocuous tone. Nevertheless, their GSRs to the tone were depressed as compared with those of Group L.

A third interpretation, one that we prefer, involves the inhibitory properties of the OR. Our hypothesis does not assume that warning instructions are a necessary condition for the inhibitory effect, as it is in the negative perception formulation. But, as in the case of the preparedness hypothesis, the OR interpretation also assumes that the inhibitory effect is central in nature rather than a localized peripheral phenomenon.

We assume that under certain conditions, unfortunately not clearly specified, a CNS process that is the correlate of what consciousness-centered psychologists described as concentration (Külpe, 1895) may be induced. A voluntary and effortful focusing of attention towards one event narrows the focus of attention and as a consequence decreases the apprehension of other stimuli.

An earlier experiment from this laboratory demonstrated striking inhibitory effects of an initial stim- ulus on a subsequent stimulus in the absence of any instructions (Maltzman et al., 1971). Students were led into a room illuminated by a single lamp. Half the students entered a high-illumination room and half entered a low-illumination room. Three different subgroups of students received a change in illumination to the other level and back every 5, 10, and $30 \mathrm{sec}$. For example, students entering the highillumination room received, without warning, a decrease in illumination following a period of constant illumination. Thirty seconds later, a return in illumination to the original high level occurred, then, after $30 \mathrm{sec}$, a decrease and $30 \mathrm{sec}$ later an increase, etc. It was found that, at all intervals and for both increases and decreases in initial illumination, the first change always evoked the larger GSR. There appeared to be an inhibitory effect of the first change upon the GSR induced by the second stimulus change. These stimulus changes occurred without warning and were innocuous. An interpretation for the results was offered in terms of assumed inhibitory properties of the OR. Such an inhibitory effect, especially after $30 \mathrm{sec}$ and involving innocuous stimulus changes, could not reasonably be interpreted in terms of peripheral GSR interference. Absence of any warning avoids a possible coping or preparedness interpretation, particularly for the first few trials, since the students have not yet had the opportunity to learn that the changes were reoccurring. Innocuous stimulus changes can result in inhibition of the GSR to other innocuous stimulus changes at long time intervals and without the service of a warning signal.

For some time now it has been noted that the OR is multiply determined and is related to highly complex processes. It is possible to distinguish among several kinds of ORs, such as voluntary ORs under a relatively high degree of verbal regulation and involuntary ORs less susceptible to verbal influence (Maltzman, 1979; Maltzman \& Mandell, 1968; Pendery \& Maltzman, 1977). Results obtained in the present experiment indicate that a voluntary $O R$ induced to the word PLANT, serving as a signal for an overt response, may inhibit the relatively involuntary OR to a tone, a novel stimulus embedded among different words. An earlier experiment (Maltzman et al., 1971) indicated that an involuntary OR to a change in illumination might inhibit another involuntary $O R$ to an opposite change in illumination that followed. Thus, there is some evidence that evocation of an OR may inhibit the occurrence of a subsequent OR expressed as GSRs. However, the conditions under which inhibition may be expected to occur are by no means clear.

It might be argued that the obtained results are internally inconsistent in that Group $T$ should have provided a significantly larger GSR to the tone than Group D on the first few trials, particularly the first. Group T, instructed to respond to PLANT, manifested a very large response to the first presentation 
of the CS word, whereas Group D manifested a small response. Therefore, Group T should have shown a smaller response to the tone on the first trial than Group D, a corresponding degree of inhibition. This difference in responsivity to the tone did not occur.

The above argument overlooks an important difference between Groups T and D and with Groups P and L. Both Group D and Group T were instructed to respond to the tone; Groups $\mathrm{P}$ and $\mathrm{L}$ were not. Instructions to respond established a dominant focus of excitability to the tone (Maltzman, 1979), which ensured an OR to its occurrence. Such was not the case in the $\mathrm{P}$ and $\mathrm{L}$ groups. In other words, to provide for inhibition of one OR by another, there must be a difference in strength, permitting the stronger OR to inhibit the weaker. This was true in Group $P$ as compared with Group L, but not in Group D as compared with Group $\mathrm{T}$.

Parametric studies systematically varying the conditions inducing the initial and subsequent ORs and the interval between them are clearly needed. Under certain conditions, facilitation of the OR to the second stimulus may occur, whereas under others inhibition will take place. This sort of apparent inconsistency is found in the early, and unfortunately neglected, literature on sensory interaction (e.g., Gilbert, 1941; Hartmann, 1934, 1935; London, 1954; Thompson, Voss, \& Brogden, 1958; Watkins, 1964, 1966). The results of these studies of sensory interactions are, we hypothesize, also the consequence of facilitating and inhibiting ORs.

The present results and their theoretical interpretation have a number of general implications for current psychophysiological and behavioral theories. An active area of psychophysiological theorizing has concerned itself with the P300 and its interpretation (e.g., Donchin, 1981). It has been suggested that the P300 may not be a measure of the OR despite great similarity in the initiating conditions of measures taken to be reflections of an OR and the P300 because the P300 does not always occur to nonsignificant or task-irrelevant stimuli. However, experiments in which task-irrelevant stimuli fail to evoke appreciable evidence of P300 characteristically engage the subject in a masking task or distraction. Under such circumstances, nonsignificant stimuli do not evoke reliable evidence of P300. When these stimuli are given significance by means of task instructions, for example, P300 is induced. Bernstein (1979) takes this sort of evidence as support for his theory that an OR does not occur to novelty but only as a consequence of significance. Both kinds of theory have failed to recognize, as the present results indicate, that ORs may be inhibited by competing task-induced ORs or states. A masking task or distraction may serve to inhibit the OR to nonsignificant stimuli and the P300 fails to occur as a consequence.
Increasing the magnitude of the OR by providing the stimuli with significance, making them task relevant, overcomes the inhibition induced by the masking task giving rise to a P300. When a masking task is absent, nonsignificant, irrelevant stimuli can evoke P300, since there are no competing inhibitory ORs present (e.g., Roth, Ford, Lewis, \& Kopell, 1976). Results from the present experiment provide a rationale for the absence of P300 to nonsignificant, taskirrelevant stimuli, when there is a masking task, thus permitting a consistent theory of the OR to account for its appearance and nonappearance, as indicated by P300 or the GSR under specified conditions.

Finally, the present results, which suggest that one OR may inhibit another OR, provide a theoretical rationale for experimental studies and behavioral therapy based upon the use of distraction. Orienting to a given stimulus or task distracts or inhibits the response to noxious or undesired stimuli (e.g., Gardner, Licklider, Weisz, 1960; Kanfer \& Goldfoot, 1966; Smith, 1977). It seems clear to us that the functional characteristics of inhibition induced by ORs are worthy of further experimental and theoretical research. It and the functional characteristic of facilitation receive far less experimental and theoretical attention than their importance merit.

\section{REFERENCES}

Bandura, A. Principles of behavior modification. New York: Holt, Rinehart and Winston, 1969.

Berlyne, D. E. Conflict, arousal and curiosity. New York: McGraw-Hill, 1960.

BERNSTE IN, A. S. The orienting reflex as novelty and significance detector: Reply to O'Gorman. Psychophysiology, 1979, 16, 263-273.

BrANDE IS, R., \& LuBow, R. E. Conditioning without awarenessagain. Bulletin of the Psychonomic Society, 1975, 5, 36-38.

Bridger, W. H., \& MANDEL, I. J. A comparison of GSR fear responses produced by threat and electric shock. Journal of Psychiatric Research, 1964, 2, 31-40.

Cook, S. W., \& Harris, R. E. The verbal conditioning of the galvanic skin reflex. Journal of Experimental Psychology, 1937, 21, 202-210.

Dawson, M. E., \& Furedy, J. J. The role of awareness in human differential autonomic classical conditioning: The necessarygate hypothesis. Psychophysiology, 1976, 3, 50-53.

Dawson, M. E., \& Grings, W. W. Comparison of classical conditioning and relational learning. Journal of Experimental Psychology, 1968, 76, 227-231.

Donchin, E. Surprise! . . . Surprise? Psychophysiology, 1981, 18, 493-513.

FUREDY, J. J. An integrative progress report on informational control in humans: Some laboratory findings and methodological claims. Australian Journal of Psychology, 1975, 27, 61-83.

Gardner, W. J., Licklider, J. C. R., \& Weisz, A. Z. Suppression of pain by sound. Science, 1960, 132, 32-33.

GILBE RT, G. M. Inter-sensory facilitation and inhibition. Journal of General Psychology, 1941, 24, 381-407.

Grings, W. W., \& Schell, A. M. Magnitude of electrodermal response to a standard stimulus as a function of intensity and proximity of a prior stimulus. Journal of Comparative and Physiological Psychology, 1969, 67, 77-82. 
Hartmann, G. W. The facilitating effect of strong general illumination upon the discrimination of pitch and intensity differences. Journal of Experimental Psychology, 1934, 17, 813-822.

Hartmann, G. W. Gestalt psychology. New York: Ronald Press, 1935.

Kanfer, F. H., \& Goldfoot, D. A. Self-control and tolerance of noxious stimulation. Psychological Reports, 1966, 18, 79-85.

KüLPE, O. Outlines of psychology. New York: Macmillan, 1895. (Republished: New York: Arno Press, 1973.)

London, I. D. Research on sensory interaction in the Soviet Union. Psychological Bulletin, 1954, 51, 531-568.

LYKKEN, D. T., \& TELLEGEN, A. On the validity of the perception hypothesis. Psychophysiology, 1974, 11, 125-132.

Maltzman, I. Orienting in classical conditioning and generalization of the galvanic skin response to words: An overview. Journal of Experimental Psychology: General, 1977, 106, 111-119.

Maltzman, I. Orienting reflexes and significance: A reply to O'Gorman. Psychophysiology, 1979, 16, 274-282.

Maltzman, I., Gould, J., Barnett, O. J., Raskin, D. C., \& WolFF, C. Classical conditioning components of the orienting reflex to words using innocuous and noxious unconditioned stimuli under different conditioned stimulus-unconditioned stimulus intervals. Journal of Experimental Psychology: General, 1977, 106, 171-212.

Maltzman, I., Harris, L., Ingram, E., \& Wolff, C. A primacy effect in the orienting reflex to stimulus change. Journal of Experimental Psychology, 1971, 87, 202-206.

Maltzman, I., \& Mandell, M. P. The orienting reflex as a predictor of learning and performance. Journal of Experimental Research in Personality, 1968, 3, 99-106.

Maltzman, I., Weissbluth, S., \& WolfF, C. Habituation of orienting reflexes in repeated GSR semantic conditioning sessions. Journal of Experimental Psychology: General, 1978, 107, 309-333.

Maltzman, I., \& Wolff, C. Preference for immediate versus delayed noxious stimulation and the concomitant GSR. Journal of Experimental Psychology, 1970, 83, 76-79.

Mowrer, O. H. A stimulus-response analysis of anxiety and its role as a reinforcing agent. Psychological Review, 1939, 46, 553-565.

O'Gorman, J. G. The orienting reflex: Novelty or significance detector? Psychophysiology, 1979, 16, 253-262.

Pendery, M., \& Maltzman, I. Instructions and the orienting reflex in "semantic conditioning" of the galvanic skin response in an innocuous situation. Journal of Experimental Psychology: General, 1977, 106, 120-140.

Pendery, M., \& Maltzman, I. Verbal conditioning and extinction of the GSR index of the orienting reflex. Physiological Psychology, 1979, 7, 185-192.

Razran, G. Mind in evolution. Boston: Houghton Mifflin, 1971.

Roth, W. T., Ford, J. M., Lewis, S. J., \& Kopell, B. S. Effect of stimulus probability and task-relevance on eventrelated potentials. Psychophysiology, 1976, 13, 311-317.

Sмiтн, M. J. Kicking the fear habit. New York: Dial Press, 1977.

Sokolov, E. N. Perception and the conditioned reflex. New York: Macmillan, 1963.

Sokolov, E. N. The modeling properties of the nervous system. In M. Cole \& I. Maltzman (Eds.), Handbook of contemporary Soviet psychology. New York: Basic Books, 1969.

Ste Klova, R. P. On the relationship between the change in light sensitivity of the eye and depression of alpha rhythm in the course of presentation of auditory stimuli. In L. G. Voronin, A. Leontiev, A. R. Luria, E. N. Sokolov, \& O. S. Vinogradova (Eds.), Orienting reflex and exploratory behavior. Washington, D.C: American Institute of Biological Sciences, 1965.

Stern, J. A., \& W Alrath, L. C. Orienting responses and conditioning of electrodermal responses. Psychophysiology, 1977, 14, 334-342.

Thompson, R. F., Voss, J. F., \& Brogden, W. J. Effect of brightness of simultaneous visual stimulation on absolute auditory sensitivity. Journal of Experimental Psychology, 1958, 55, 45-50.

Thorndike, E. L., \& Lorge, I. The teacher's word book of 30,000 words. New York: Bureau of Publications, Teachers College, Columbia University, 1944.

Voronin, L. G., Leontiev, A. N., Luria, A. R., Sokolov, E. N., \& Vinogradova, O. S. (Eds.). Orienting reflex and exploratory behavior. Washington, D.C: American Institute for Biological Sciences, 1965.

WAID, W. M. Perceptual preparedness in man: Brief forewarning reduces electrodermal and psychophysical response to noxious stimulation. Psychophysiology, 1979, 16, 214-221.

WATKins, W. H. Effect of certain noises upon detection of visual signals. Journal of Experimental Psychology, 1964, 67, 72-75.

Watkins, W. H. Photic facilitation of tonal signal detection in a forced situation. Psychonomic Science, 1966, 6, 477-478.

(Manuscript received January 13, 1981; revision accepted for publication May 14, 1982.) 